\title{
Renal Cell Carcinoma (RCC) Tumors Display Large Expansion of Double Positive (DP) CD4+CD8+ T Cells With Expression of Exhaustion Markers
}

\section{OPEN ACCESS}

Edited by:

Cristina Bonorino,

Pontifícia Universidade Católica do Rio

Grande do Sul, Brazil

Reviewed by:

Tomasz Zal,

University of Texas MD Anderson

Cancer Center, United States

Umaimainthan Palendira,

Centenary Institute Australia, Australia

*Correspondence:

Laurence C. Menard

laurence.menard@bms.com

Specialty section This article was submitted to T Cell Biology,

a section of the journal

Frontiers in Immunology

Received: 27 July 2018 Accepted: 05 November 2018 Published: 26 November 2018

Citation:

Menard LC, Fischer P, Kakrecha B, Linsley PS, Wambre E, Liu MC

Rust BJ, Lee D, Penhallow B, Manjarrez Orduno $N$ and Nadler SG (2018) Renal Cell Carcinoma (RCC) Tumors Display Large Expansion of Double Positive (DP) CD4+CD8+ T Cells With Expression of Exhaustion Markers. Front. Immunol. 9:2728. doi: 10.3389/fimmu.2018.02728

\section{Laurence C. Menard ${ }^{1 *}$, Paul Fischer ${ }^{1}$, Bijal Kakrecha ${ }^{1}$, Peter S. Linsley ${ }^{2}$, Erik Wambre ${ }^{2}$, Maochang C. Liu' ${ }^{2}$, Blake J. Rust ${ }^{2}$, Deborah Lee ${ }^{1}$, Becky Penhallow ${ }^{1}$, Nataly Manjarrez Orduno ${ }^{1}$ and Steven G. Nadler ${ }^{1}$}

${ }^{1}$ Translational Medicine, Bristol-Myers Squibb, Princeton, NJ, United States, ${ }^{2}$ Benaroya Research Institute at Virginia Mason, Seattle, WA, United States

Checkpoint inhibitors target the inhibitory receptors expressed by tumor-infiltrating $T$ cells in order to reinvigorate an anti-tumor immune response. Therefore, understanding T cell composition and phenotype in human tumors is crucial. We analyzed by flow cytometry tumor-infiltrating lymphocytes (TILS) from two independent cohorts of patients with different cancer types, including RCC, lung, and colon cancer. In healthy donors, peripheral T cells are usually either CD4+ or CD8+ with a small percentage of CD4+ CD8+ DP cells $(<5 \%)$. Compared to several other cancer types, including lung, and colorectal cancers, TILs from about a third of RCC patients showed an increased proportion of DP CD4+CD8+ T cells ( $>5 \%$, reaching $30-50 \%$ of T cells in some patients). These DP T cells have an effector memory phenotype and express CD38, 4-1BB, and HLA-DR, suggesting antigen-driven expansion. In fact, TCR sequencing analysis revealed a high degree of clonality in DP T cells. Additionally, there were high levels of PD-1 and TIM-3 expression on DP T cells, which correlated with higher expression of PD-1 and TIM-3 in conventional single positive CD8 T cells from the same patients. These results suggest that DP T cells could be dysfunctional tumor-specific $T$ cells with the potential to be reactivated by checkpoint inhibitors.

Keywords: renal cell carcinoma (RCC), CD4+CD8+ T cells, T cell dysfunction, TIM-3, PD-1, clonal expansion

\section{INTRODUCTION}

Checkpoint inhibitors target inhibitory receptors expressed by tumor-infiltrating $\mathrm{T}$ cells in order to reinvigorate an anti-tumor immune response. Despite unprecedented response rates to anti-CTLA4 and anti-PD-1/PDL1 agents in some types of advanced cancers such as melanoma or non-small cell lung cancer (1-4), responses across tumor types are highly variable (5). To effectively reject tumor cells, immunogenic antigens have to be generated $(5,6)$ and accessible to antigen-specific $\mathrm{T}$ cells, which need to infiltrate the tumor. In addition, for the therapy to be effective, there presumably have to be indications that the targeted pathway is engaged [PDL1 expression in tumor samples (4) or PD-1 expression by T cells (7) for instance]. The presence or absence of each of these prerequisites is highly variable across tumor types and patients. Even tumor-infiltrating CD8 T cells are a highly heterogeneous subset (8). Hence, a better understanding of the heterogeneity of tumor-infiltrating $\mathrm{T}$ cell function and phenotype across tumor types is crucial to guide therapies and tumor selection for better response rates. 
Outside the thymus, CD4 and CD8 expression on T cells are usually mutually exclusive and tightly regulated by the transcription factors Runx3 and ThPOK (9, 10).Nevertheless, $\mathrm{CD} 4+\mathrm{CD} 8+$ double positive (DP) $\mathrm{T}$ cells have been described in intestinal tissue (11), in the blood and/or tissues of patients with chronic viral infections (human immunodeficiency virus, cytomegalovirus and hepatitis C virus) (12-14) and in some cancers (melanoma, breast, and metastatic colorectal cancer) (15-19). Both in the context of chronic viral infection and cancer, several studies reported an enrichment of antigen-specific cells in the DP T cell compartment suggesting that DP $\mathrm{T}$ cells may be important for mediating the anti-viral/tumor response.

Here, we characterize the frequencies and phenotypes of DP $\mathrm{T}$ cell subsets across several tumor types, and we describe the expansion of DP T cells in RCC tumors. DP T cells display an antigen-experienced phenotype with expression of activation markers and evidence of antigen-driven clonal expansion. In addition, high expression of inhibitory receptors PD-1 and TIM3 make these patients potential good candidates for checkpoint inhibitor therapies.

\section{MATERIALS AND METHODS}

\section{Patient Cohorts and Samples}

Three independent cancer patient cohorts were analyzed for this study: a discovery cohort, evaluating tumor-infiltrating lymphocytes on lung cancer, colorectal cancer (CRC) and RCC tumor samples; a replication cohort focused on RCC, with 18 non-RCC tumor samples for comparison; a public dataset of densely-phenotyped RCC TILs (20). Samples for the discovery and replication cohorts were provided by Folio-Conversant Bio (AL), MT Group (CA), Rutgers-CINJ or the Benaroya Research Institute. All patients gave written informed consent at time of sample collection according to IRB protocols of each provider. Patient demographics and cancer stages are indicated in Tables 1, 2 for discovery and replication cohorts, respectively. Patients were not on checkpoint inhibitors at the time of collection, and except for one patient with CRC in the discovery cohort and one patient with a gastrointestinal stromal tumor in the replication cohort, were not receiving chemotherapy. Most tumors were stage I and II, and not metastatic. The replication cohort was focused on RCC.

Tumor samples and matching blood were received and processed within $24 \mathrm{~h}$ of collection. To isolate tumor-infiltrating lymphocytes (TILs), tumors were dissociated either with the Tumor Dissociation Kit (Miltenyi Biotec) for the discovery cohort or with a mild cocktail of collagenase I $(50 \mathrm{U} / \mathrm{ml})$, II $(18 \mathrm{U} / \mathrm{ml}), \mathrm{IV}(52 \mathrm{U} / \mathrm{ml})$ and elastase $(0.1 \mathrm{U} / \mathrm{ml})$ (Worthington Biochemical) for the replication cohort.

\section{Flow Cytometry}

For the discovery cohort, ACD-whole blood pre-treated with $\mathrm{RBC}$ lysis buffer (Biolegend) and freshly isolated TILs were washed with 1X PBS and stained for viability with LIVE/DEAD Fixable Near-IR Dead Cell kit (Thermo Fisher Scientific). Nonspecific binding was prevented by blocking Fc receptors with Human AB serum (Gem Cell). Cells were stained with an antibody cocktail that contained CD3-BUV395(SK7, BD), CD4BV785 (OKT4, Biolegend), CD8a-BV605 (SK1, BD), CD45AF700 (HI30, BD).

For the replication cohort, heparin whole blood pretreated with red blood cells sedimentation buffer (Miltenyi) and freshly isolated TILs were washed with 1X PBS and stained for viability with LIVE/DEAD Fixable Near-IR Dead Cell dye (Thermo Fisher Scientific). Non-specific binding was prevented by blocking Fc receptors with Human Gamma Globulin (Jackson ImmunoResearch). Cells were stained with an antibody cocktail that contained CD45-BV480 (HI30, BD), CD3BUV496 (UCHT1, BD), CD4-AF700 (SK3, Biolegend), CD8BUV395 (RPA-T8, BD), CD45RO-BV421 (UCHL1, Biolegend), CCR7-BV711 (G043H7, Biolegend), PD-1-APC (MIH4, BD), GITR-BV785 (6G10-BMS), TIGIT-PE (MBSA43, eBioscience), ICOS-PE-Cy7 (C398.4A, Biolegend), TIM-3-BB515 (7D3, BD) and OX40-BV605 (ACT35, Biolegend). When enough TIL were recovered, a second panel containing CD45-BV480 (HI30, BD), CD3-BUV496 (UCHT1, BD), CD4-AF700 (SK3, Biolegend), CD8-BUV395 (RPA-T8, BD), CD45RO-BV421 (UCHL1, Biolegend), CCR7-BV711 (G043H7, Biolegend), PD-1APC (MIH4, BD), and CD38-PE-Cy7 (HB7, Biolegend) was also used. Stained cells were then washed and fixed with $1 \mathrm{x}$ BD lyse buffer (BD Biosciences). For both cohorts, samples were run on a LSR Fortessa (BD). Data analysis was performed with FlowJo or Cytobank.

\section{Spanning-Tree Progression Analysis of Density-Normalized Events (SPADE)}

The SPADE algorithm (21) was run in Cytobank on single viable CD45+CD3+ gated cells from 10 RCC samples with more than $5 \% \mathrm{DP} T$ cells from the replication cohort, using surface markers (CD4, CD8, TIGIT, ICOS, TIM-3, PD-1, CD45RO, CCR7, OX40, GITR). The down-sampled event target was $10 \%$ and the target number of nodes was 100 .

\section{Analysis of Mass Cytometry Dataset}

Publicly available data from RCC TIL were uploaded from https://premium.cytobank.org/cytobank/experiments/101725 into Cytobank for gating and analysis.

\section{Single Cell Sort And TCR Analysis}

Single cells were sorted directly into SMARTseq v4 (Takara) lysis buffer to release RNA. Reverse transcription was performed followed by PCR amplification to generate full length amplified cDNA. Sequencing libraries were constructed using a modified protocol of the NexteraXT DNA sample preparation kit (Illumina) to generate Illumina-compatible barcoded libraries. Libraries were pooled and quantified using a Qubit ${ }^{\circledR}$ Fluorometer (Life Technologies). Dual-index, singleread sequencing of the pooled libraries was carried out on a HiSeq2500 sequencer (Illumina) with 58-base reads, using HiSeq v4 Cluster and SBS kits (Illumina) with a target depth of 1 million reads per sample. FASTQs were aligned to a human reference genome to generate gene counts. 
TABLE 1 | Patient demographics and clinical annotations for discovery cohort.

\begin{tabular}{|c|c|c|c|c|c|c|c|c|}
\hline Cancer type & Patients, $n$ & females, \% & Mean age (SD) & Stage I (\%) & Stage II (\%) & Stage III (\%) & Stage IV (\%) & $\begin{array}{c}\text { Chemotherapy and } \\
\text { radiotherapy at } \\
\text { collection, } n\end{array}$ \\
\hline RCC & 21 & 35 & $59(12)$ & 53 & 16 & 26 & 5 & 0 \\
\hline CRC & 16 & 31 & $69(13)$ & 6 & 25 & 56 & 13 & 1 \\
\hline Lung & 16 & 44 & $70(9)$ & 38 & 25 & 37 & 0 & 0 \\
\hline
\end{tabular}

TABLE 2 | Patient demographics and clinical annotations for replication cohort.

\begin{tabular}{|c|c|c|c|c|c|c|c|c|}
\hline Cancer type & $\begin{array}{c}\text { Patients, } \boldsymbol{n} \\
\text { (with annotations) }\end{array}$ & females, \% & Mean age (SD) & Stage I (\%) & Stage II (\%) & Stage III (\%) & Stage IV (\%) & $\begin{array}{c}\text { Chemotherapy at } \\
\text { collection, } n\end{array}$ \\
\hline $\mathrm{RCC}$ & $23(21)$ & 21 & $60(13.5)$ & 71 & 24 & 5 & 0 & 0 \\
\hline Others & $18(14)$ & 82 & 64 (14) & 42 & 21 & 7 & 0 & 1 \\
\hline
\end{tabular}

\section{Statistics}

Statistical analyses were performed with GraphPad Prism 7. For comparisons between subsets from the same samples, the Wilcoxon test was used. $P$ values were adjusted for 3 comparisons. Correlations between continuous variables were analyzed with Spearman. A $P$-value of 0.05 or lower was considered significant.

To compare the degree of clonal expansion between different groups with different numbers of libraries/cells, we repetitively down-sampled (100x) to a reduced, standard sample size $(N \sim 25$ cells), and calculated the mean fraction of enrichment for each cell subset from each donor in the down-samplings. Differences between the mean fractions of expanded TCRs for the different subsets were evaluated with a two-sided $t$-test. Statistical differences in TCR junction sharing between subsets were evaluated with a Fischer exact test.

\section{RESULTS}

\section{RCC Tumors Display a Large Expansion of CD4+CD8+ Double Positive T Cells}

We initially analyzed the proportion of TIL T cell subsets based on CD4 and CD8 expression in a discovery cohort of 21 RCC, 16 lung cancer and 16 CRC samples. Cell doublets were carefully excluded as shown on the gating strategy in Figure 1A. Although $\mathrm{CD} 4+\mathrm{CD} 8+\mathrm{DP} \mathrm{T}$ cells represented less than $2 \%$ of $\mathrm{T}$ cells in a majority of tumor samples, frequencies of CD4+CD8+ DP T cells above $5 \%$ of $\mathrm{T}$ cells were observed in $6 / 21$ of RCC samples, 1/16 lung cancer and 1/16 CRC samples (Figure 1B). CD4 and CD8 median fluorescence intensity (MFI) in DP $\mathrm{T}$ cells were normalized to CD4 and CD8 MFI of conventional CD4 and CD8 $T$ cells from the same samples, respectively, for comparison. All RCC and CRC DP T cells had a CD8 expression level close to conventional CD8+CD4- T cells (ratio of CD8 MFI in DP over CD8 MFI in CD8: 0.77-1.1) (Figure 1C). CD4 was expressed at lower level on DP $\mathrm{T}$ cells than on $\mathrm{CD} 4+\mathrm{CD} 8$ - $\mathrm{T}$ cells (ratio of CD4 MFI in DP over CD4 MFI in CD4: 0.28-0.57). The expanded DP T cell subset observed in the lung cancer patient $(6.5 \%$ of $\mathrm{T}$ cells) showed a different profile with CD4 expression similar to CD4 T cells (ratio of CD4 MFI in DP over CD4 MFI in CD4: 0.97) and significantly lower CD8 expression than CD8 T cells (ratio of CD8 MFI in DP over CD8 MFI in CD8 cells: 0.33 ) (Figures 1C,D). Thus, the DP T cells observed in the 6 RCC and $1 \mathrm{CRC}$ samples were $\mathrm{CD} 8+\mathrm{CD} 4^{\text {low }}$, whereas the DP T cells from the lung sample were $\mathrm{CD} 4+\mathrm{CD} 8^{\text {low }}$ and likely constitute a distinct subset of DP T cells $(13,22)$.

Given that the expanded DP $\mathrm{T}$ cell population occurred more commonly in RCC vs. other tumor types, we obtained a replication cohort focused on RCC tumors that we compared to 18 diverse, non-RCC tumor samples. Consistent with data from the discovery cohort, frequencies of DP T cells above $5 \%$ of T cells were also observed in 10/23 RCC samples, reaching up to $62 \%$ of $\mathrm{T}$ cells in a sample, with no DP $\mathrm{T}$ cell expansion in the other tumor types (Figure 2A). By contrast, analysis of matching blood did not reveal higher frequencies of circulating DP T cells in the blood of patients with expanded tumor DP T cells, suggesting that these DP T cells may not recirculate (Figures 2B,C).

Analysis of TIL T-cell subsets across several tumor types in 2 independent sample sets revealed an expansion of CD4+CD8+ T-cell subset enriched in RCC. We thus went on to characterize further DP T cells in the replication cohort.

\section{No Correlation Between DP Expansion and Tumor Stage}

Histology and pathology data in the replication cohort were available for 18 out of 23 samples. Samples with more than 5\% DP $\mathrm{T}$ cells were all of the clear cell RCC type. Stage and grade were similar between patients with and without expanded DP T cells. Age and tumor size did not correlate either with the expansion of DP T cells (Table 3). We were thus unable to correlate the expansion of DP T cells with any of the available histology and pathology data. In addition, RCC samples in both the discovery and replication cohorts were all treatment naive, which rules out a potential effect of treatment on the expansion of DP T cells (Tables 1, 2).

\section{Double Positive T Cells Are a Subset of CD8 T Cells With an Effector Memory Phenotype}

In order to determine if DP $\mathrm{T}$ cells are either an independent subset of T cells or a subset of CD8 T cells that upregulated CD4 or vice versa, we performed clustering analysis of the phenotype 

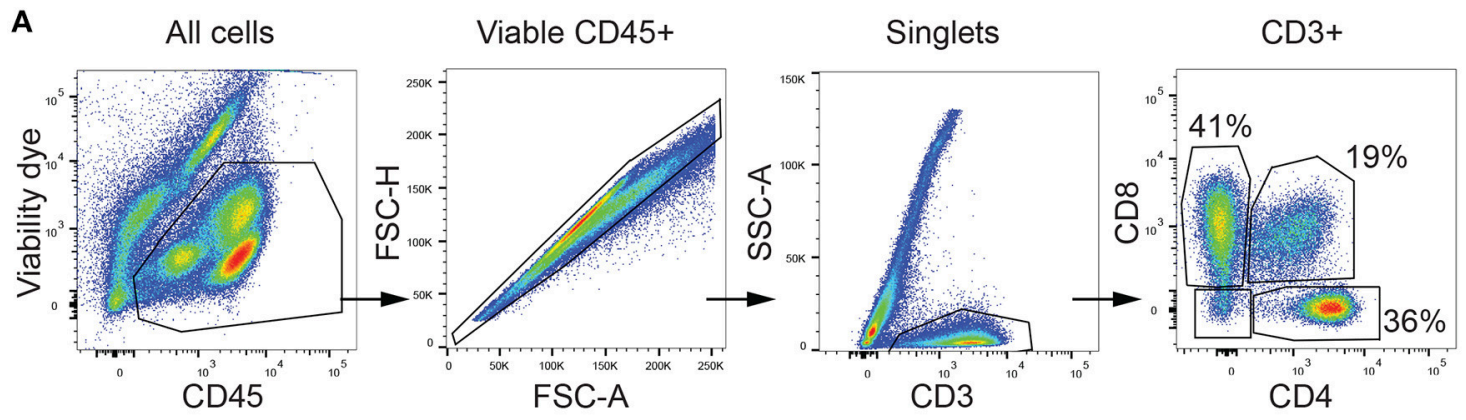

$$
\text { B }
$$

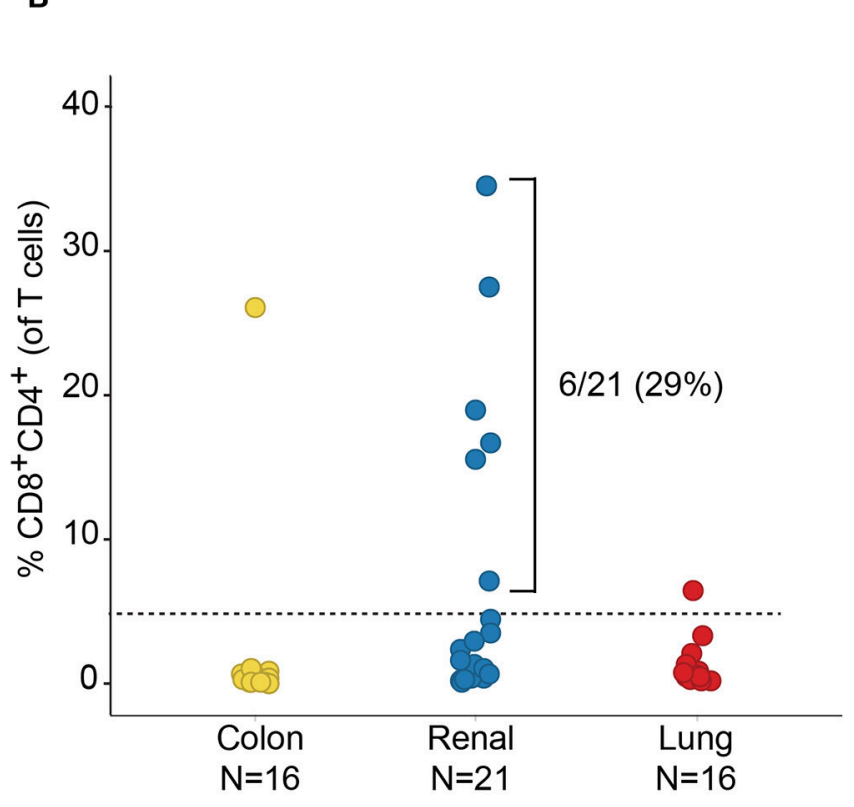

C
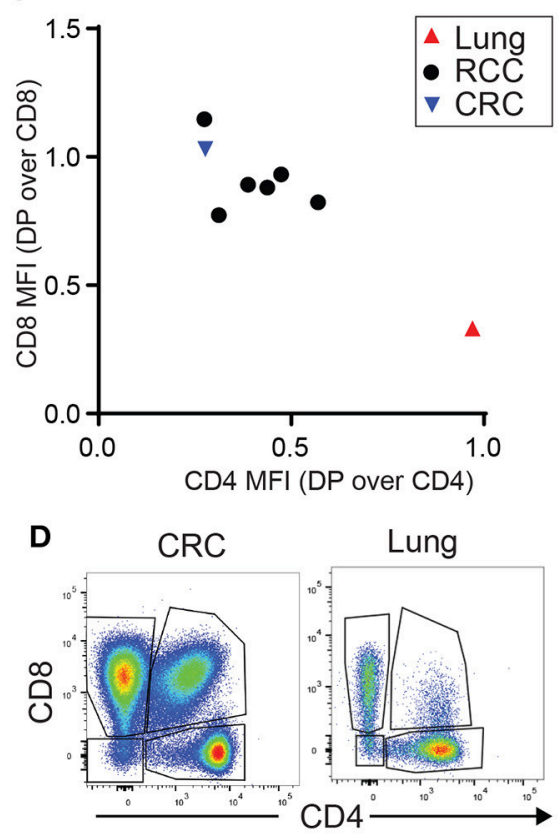

FIGURE 1 | Expansion of DP T cells in RCC (discovery cohort). (A) Example of gating strategy for flow cytometry analysis of a RCC sample: CD4 and CD8 expressions were visualized after gating on viable CD45+ single CD3+ T cells. (B) Frequencies of DP CD4+CD8+ T cells in TILs from a set of CRC, RCC and lung tumors. Horizontal line is the $5 \%$ cut-off. (C) Plot representing ratio of CD4 MFI in DP over CD4+CD8- T cells on x-axis and of CD8 MFI in DP over CD4-CD8+ on y-axis. Each dot represents a sample with $>5 \%$ DP T cells as identified in Figure 1B. (D) Dot plots of CD4 vs. CD8 expression in the CD3+ gate of the CRC and the lung tumor samples with $>5 \%$ DP.

of DP T cells with the Spanning-tree Progression Analysis of Density-normalized Events (SPADE) algorithm using surface markers (CD4, CD8, TIGIT, ICOS, TIM-3, PD-1, CD45RO, CCR7, OX40, GITR) in 10 samples of the replication cohort with more than 5\% DP T cells (Figure 2A). CD4+ and CD8+ T cells mostly clustered in different areas or "bubbles" according to CD8 and CD4 expression. Interestingly, DP T cells clustered with conventional CD4-CD8 $+\mathrm{T}$ cells as revealed by CD4 expression within the $\mathrm{CD} 8$ bubble, suggesting that they are a subset of CD8+ T cells (Figure 3A, Supplementary Figure 1). Expression of CD4 and CD8 is under the tight regulation of transcription factors that prevent co-expression, except in thymic cells during early development. Analysis of CD45RO and CCR7 expression showed that DP T cells were mostly CD45RO+CCR7-, characteristic of an effector memory phenotype, meaning that DP $\mathrm{T}$ cells are antigen experienced and unlikely to be recently egressed thymic DP T cells (Figures 3B,C).

\section{Double Positive T Cells Express Activation Markers}

CD38 is an activation marker upregulated by inflammatory cytokines (23) and potentially enriched in antigen-experienced $\mathrm{T}$ cells $(24,25)$. Blood HLA-DR+CD38+ CD8 T cells show expansion of tumor-infiltrating clones following anti-PD1 treatment (26). Enough TIL were recovered from 8 out of the 10 RCC samples with expanded DP $\mathrm{T}$ cells from the replication cohort to run a second flow cytometry panel to measure CD38 expression. Both frequencies of CD38+ cells and median fluorescence intensity (MFI) were highest in DP $\mathrm{T}$ cells, followed by CD8, then CD4 T cells 

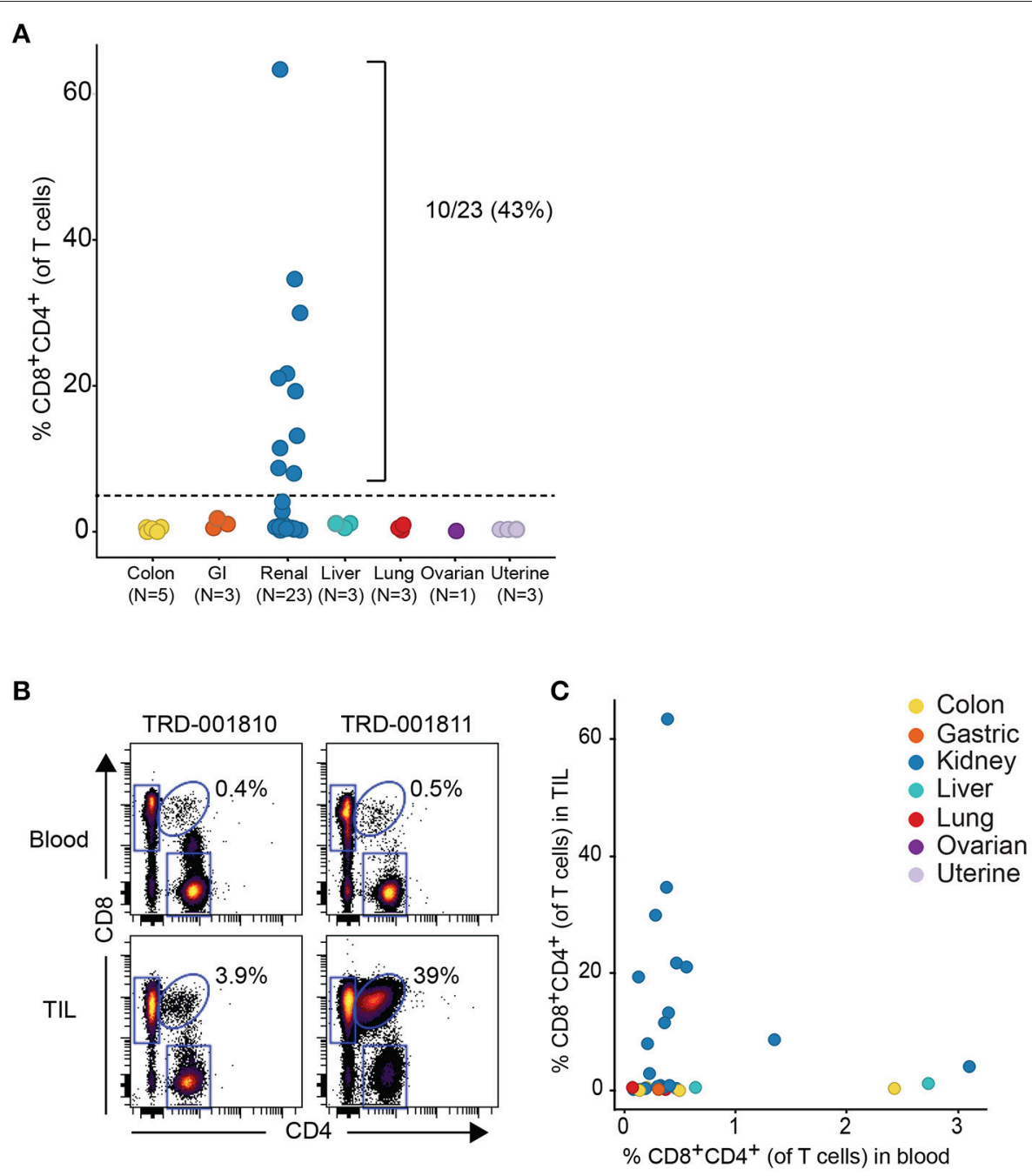

FIGURE 2 | Expansion of DP T cells in RCC (replication cohort). (A) Summarized frequencies of DP T cells in a replication RCC-enriched cohort that included TIL samples from 23 RCC vs. 18 non-RCC tumors. The dotted line at $5 \%$ is the arbitrary cutoff used to determine expansion of DP T cells. (B) Representative example of dot plots for CD4 and CD8 expression, gated on single viable CD45+CD3+ T cells, from 2 RCC TILs and matching blood samples. The elliptical gate shows the presence of CD4+CD8+ DP T cells. (C) Frequencies of DP T cells in blood (x-axis) vs. TILs (y-axis).

(Figures $4 \mathrm{~A}-\mathrm{C}$ ). In order to gain more information on the activation status of DP T cells, we analyzed a publicly available mass cytometry dataset that contains data on expression of additional activation markers HLA-DR, 4-1BB, and Ki-67 in RCC T cell subsets (20). In this dataset, 24/63(38\%) RCC samples showed more than $5 \%$ of CD4+/loCD8+ DP T cells, confirming the expansion of this subset in RCC (Figure 4D, Supplementary Figure 2). Similarly to the SPADE analysis performed on the flow cytometry expression data generated on the replication cohort, SPADE trees generated on this mass cytometry dataset showed clustering of DP T cells within the CD8 "bubble" (Supplementary Figure 3). The frequency of Ki$67+$ cells was higher in DP T cells than in CD8 T cells, and in CD8 $\mathrm{T}$ cells compared to CD4 T cells (Figures 4E,F). HLA-DR and 4-1BB (27), markers of activation believed to be enriched for antigen-specific $\mathrm{T}$ cells, were also expressed at higher levels by DP T cells compared to conventional CD8 and CD4 T cells (Figures 4G-J).

\section{Double Positive T Cells Show High Level of Clonal Expansion}

The enrichment of DP TIL T cells with an activated/antigen experienced phenotype suggests antigen-driven expansion of $\mathrm{T}$ cells. To confirm this hypothesis, TCR clonal analysis was performed. An antigen-driven expansion should lead to an increase in the frequency of specific clones and a diminished diversity. Single CD4+, CD8+, and DP T cells were sorted from 3 RCC TIL samples. Libraries were obtained for single CD4, CD8, and DP T cells from 2 donors and for single CD4 and DP T cells from the third donor. TCR $\alpha$ and TCR $\beta$ chains sequencing analysis revealed that in each of the 3 donors, many TCR pairs were shared between DP T cells, showing relatively 
TABLE 3 | Demographics and clinical annotations for 18 RCC patients with more or less than 5\% DP T cells from the replication cohort.

\begin{tabular}{lcc}
\hline Parameter & $\mathbf{D P}<\mathbf{5 \%}(\boldsymbol{n}=\mathbf{9 )}$ & $\mathbf{D P}>\mathbf{5 \%}(\boldsymbol{n}=\mathbf{9})$ \\
\hline Mean age (SD) & $61(14)$ & $58(13)$ \\
Female, $n$ (\%) & $1(11)$ & $3(33)$ \\
Stage, $n$ & & 7 \\
I & 6 & 2 \\
II & 2 & 0 \\
III & 1 & 0 \\
Grade, $n$ & 1 & 6 \\
1 & 4 & 2 \\
2 & 1 & 1 \\
$2-3$ & 2 & 0 \\
3 & 1 & $9(100)$ \\
4 & $5(56)$ & $5.6(1.9)$ \\
Histology: clear cell vs. Others, $n(\%)$ & $7.6(6.2)$ & \\
Mean tumor size (SD) & & \\
\hline
\end{tabular}

higher clonal expansion compared to CD4 and CD8 T cell subsets and suggesting antigen-driven expansion of DP $\mathrm{T}$ cells. By contrast, the CD4 $\mathrm{T}$ cell subset showed limited clonal expansion (Figures 5A,B). Analysis of CD8+ T cells in 2 of the 3 donors also revealed that many clones are shared between CD8+ and DP T cells, consistent with the hypothesis that they are the same or closely related subsets (Figure 5C). $C D 8 A$ and $C D 8 B$ were co-expressed in single DP and CD8 T cells, indicating that $\mathrm{CD} 8 \alpha / \mathrm{CD} 8 \beta$ heterodimers are likely expressed in both subsets (Supplementary Figure 4).

\section{Double Positive T Cells Express Inhibitory Receptors}

Our results point to an antigen-driven expansion of DP and CD8 T cells in some RCC tumors, and yet, those tumors are not rejected, suggesting strong inhibitory mechanisms. Expression of inhibitory receptors on DP T cells was therefore examined. HAVR2, which codes for TIM-3, TIGIT, and LAG3 were generally expressed in single DP $\mathrm{T}$ cells from the 3 donors analyzed for TCR sequence analysis, at higher levels than single CD4 T cells and higher or similar levels as single CD8 T cells (Figure 6). EOMES, a key transcription factor in the regulation of CD8 T cell effector function (28), was also expressed at higher level in DP T cells than in CD4 T cells (Figure 6). DP T cells expressed ITGAE (codes for CD103), and CD69, but not SELL, KLF2, and $S 1 P R 1$, suggesting a tumor resident phenotype $(29,30)$ (Supplementary Figure 5).

Expression of TIM-3 and TIGIT, as well as PD-1, another inhibitory receptor was analyzed by flow cytometry on $\mathrm{T}$ cell subsets from the DP $\mathrm{T}$ cells in the replication cohort. Close to $100 \%$ of $\mathrm{DP} \mathrm{T}$ cells in almost all donors expressed PD1. In addition, PD-1 was highly co-expressed with TIM-3 (Figures 7A,B). TIGIT was also expressed at high level in the DP subset (Figure 7C). In addition, conventional CD8+ T cells from samples with expanded DP T cells also showed high expression of PD-1 and TIM-3 (Figures 7D-F).

\section{DISCUSSION}

Here we describe the expansion of CD4+CD8+ DP T cells in RCC (29-43\% of samples) in three independent data sets. The other tested tumor indications, mainly lung and CRC, did not show a significant increase in DP T cells. DP $\mathrm{T}$ cells appeared to be a subset of clonally expanded CD8 $+\mathrm{T}$ cells that expressed both activation markers (HLA-DR, CD38, 4-1BB, CD137, Ki-67) and inhibitory markers (PD-1, TIM-3, and TIGIT).

Clustering analyses of flow cytometry data suggest that DP $\mathrm{T}$ cells are a subset of CD8 T cells that upregulate CD4. CD4 can be re-expressed upon TCR stimulation (31) and DP T cells are expanded in the blood of patients chronically infected with viruses and enriched in virus-specific T cells (12-14). The meaning of CD4 upregulation on CD8 T cells is unknown. CD4 expression on CD8 $\mathrm{T}$ cells was shown to enhance cytotoxic antiviral responses (12). Decreased CD4 help may favor CD8 T cell exhaustion (32) therefore CD4 upregulation could be a way to reverse CD8 $\mathrm{T}$ cell exhaustion. We could speculate that CD4 expression on DP T cells might allow them to respond to MHCII antigens in an effort to overcome resistance mediated by $\mathrm{MHCI}$ loss observed in many tumor types (33). It would then be interesting to evaluate an association between MHCI loss and expansion of DP T cells in RCC. Could DP T cell then have a helper function? CD40L, which was upregulated on lines derived from DP T cells from melanoma samples, provided helper $\mathrm{T}$ function to DP $\mathrm{T}$ cells, leading to activation of $\mathrm{B}$ cells and increase in DC cross-presentation functions (18). Upregulated CD4 and CD40L on CD8 could thus perhaps be a mechanism for CD8 to counterbalance the negative effect of the tumor microenvironment on CD8 activation. A deeper understanding of this peculiar subset of CD8 $\mathrm{T}$ cells will likely uncover new tumor $\mathrm{T}$ cell biology.

Why were we able to identify these cells only in RCC? Previously published reports have described expansion of DP $\mathrm{T}$ cells in breast pleural effusions (15), melanoma (16), and metastatic CRC (17). We did not have any melanoma or breast tumor samples to confirm these findings, however, the frequencies of DP $\mathrm{T}$ cells described in those tumor types were generally within $10 \%$ of $\mathrm{T}$ cells, which is a significantly lower level of expansion than what observed in RCC, where DP cells could constitute more than $60 \%$ of T cells. Besides RCC, only one CRC sample in the discovery cohort showed expansion of DP $\mathrm{T}$ cells (26\% of $\mathrm{T}$ cells) with CD4 and CD8 expression profiles similar to RCC DP T cells. This donor had intact mismatch repair protein expression and was likely micro-satellite stable. It was a stage III invasive adenocarcinoma. Additional stage III and metastatic stage IV CRC cases showed $1 \%$ or less of DP T cells. Therefore, we could not correlate the presence of these cells with metastasis as previously reported (17). In our RCC cohorts, patients with expanded DP T cells were essentially of the clear cell subtype without correlation with stage or grade.

The activated phenotype of DP T cells, taken together with the higher TCR repertoire clonality, suggest an antigen-driven expansion of DP T cells. A previous report had shown oligoclonal expansion of tumor-reactive effector memory $\mathrm{T}$ cells in TILs 

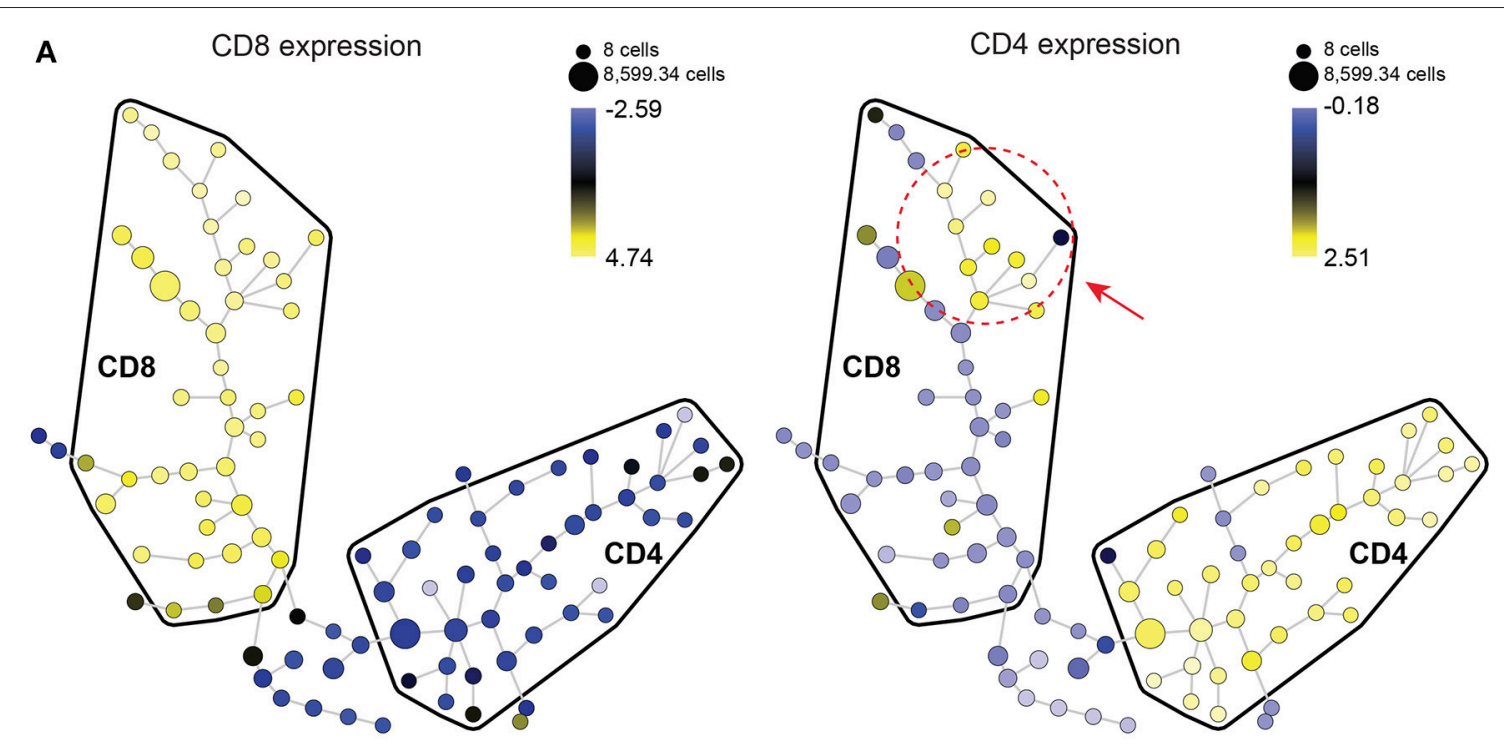

B

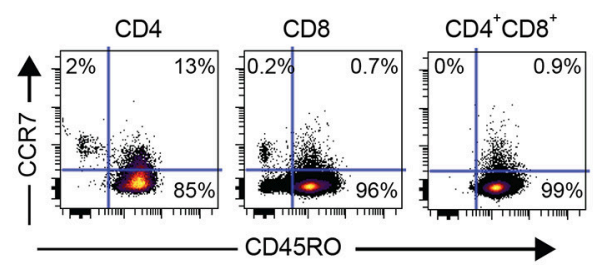

C

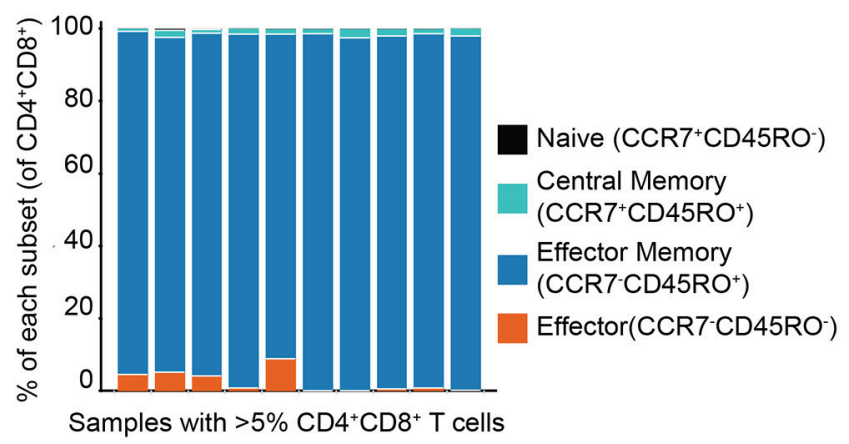

FIGURE 3 | DP T cells appear to be a subset of CD8+ T cells. (A) Representative example of a SPADE-tree generated with surface markers (CD4, CD8, TIGIT, ICOS, TIM-3, PD-1, CD45RO, OX40, GITR, CCR7) on the replication cohort in the 10 samples with $>5 \%$ DP T cells (red circle and arrow indicate zone where DP T cells cluster). The size of the nodes represents the number of cells, and the color represents the transformed median expression level of CD8 (left panel) or CD4 (right panel). (B) Representative dot plot of CD45RO (x-axis) and CCR7 (y-axis) in CD4+, CD8+, and DP gated T cells. (C) Summary of cell frequencies in each quadrant shown in (B) for DP T cells from RCC samples with $>5 \%$ DP cells (replication cohort).

from two clear cell RCC patients, although whether these cells were CD4, CD8 or DP T cells was not specified (34). RCC was found to have a higher proportion of coding frameshift mutations in a pan-cancer study, potentially leading to large amounts of neoantigens and associated with a cytotoxic and CD8 signature (35). However, according to this study, lung adenocarcinoma was also a tumor type with potentially even higher frameshift neoantigens per tumor but we did not observe $\mathrm{DP} \mathrm{T}$ cell expansion in lung adenocarcinoma. In addition, a more recent report did not confirm the positive association between frameshift mutations and $\mathrm{T}$ cell signatures in a large RCC cohort (36). Could another antigen specific to RCC explain the DP T cell expansion? Several cancer types have been associated with viral infection (head and neck or cervical cancers with human papillomavirus (HPV) or hepatic cancer with hepatitis B or C viruses, for instance) (37) although evidence for a role of oncogenic viruses in clear cell RCC is limited. Only a few studies have reported a possible link between renal cancer and HPV, hepatitis C virus, or EpsteinBarr virus infections (38) although no viral sequences were found in TCGA data from RCC samples in a recent study (37). The human genome contains a significant amount $(\sim 4.7 \%)$ of DNA from endogenous retroviruses (ERV) (39). While generally repressed in healthy tissue, expression of ERV genes can be increased in some tumors. In fact, envelop proteins from the human ERV E (HERV-E) can be re-expressed in VHLdeficient clear cell RCC tumor cells potentially triggering a $\mathrm{T}$ cell response and tumor rejection (40-42). Whether the antigens driving clonal expansion of DP T cells in this subset of RCC tumors are neoantigens or derived from ERV will have to be determined.

In addition to the expression of activation markers, DP T cells also express the inhibitory receptors PD-1 and TIM-3, which have been previously associated to $\mathrm{T}$ cell dysfunction 

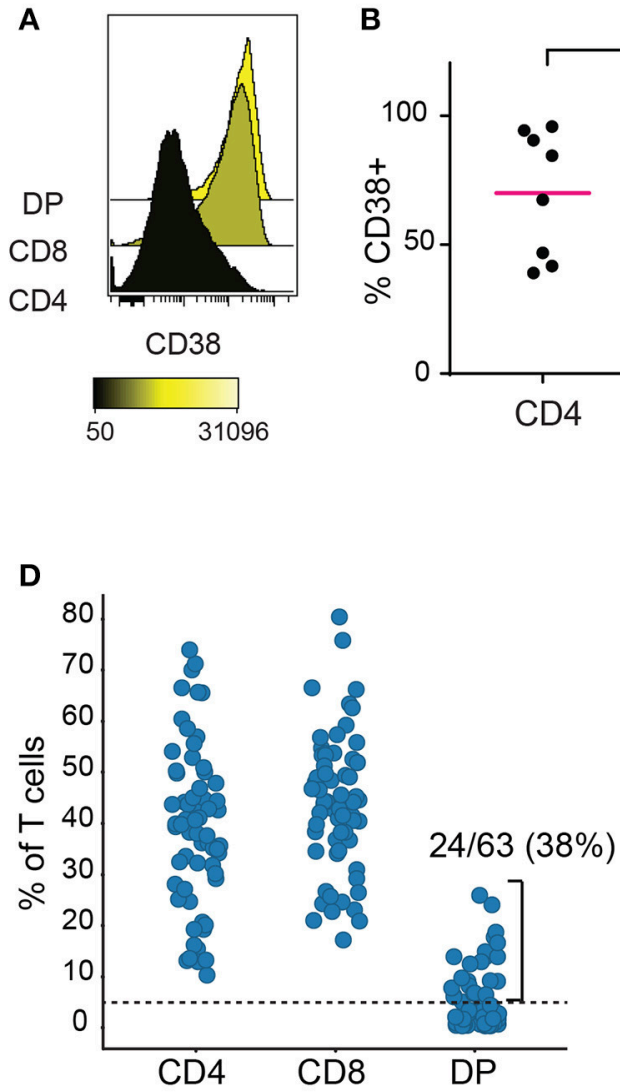

G $\quad \operatorname{RCC} 26 \quad \operatorname{RCC} 36 \quad \operatorname{RCC} 58$
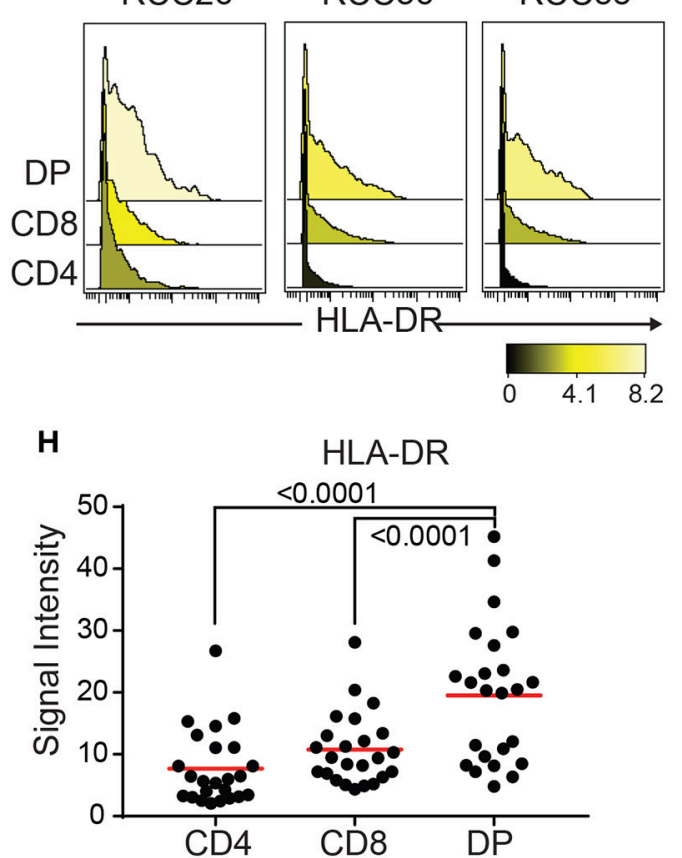
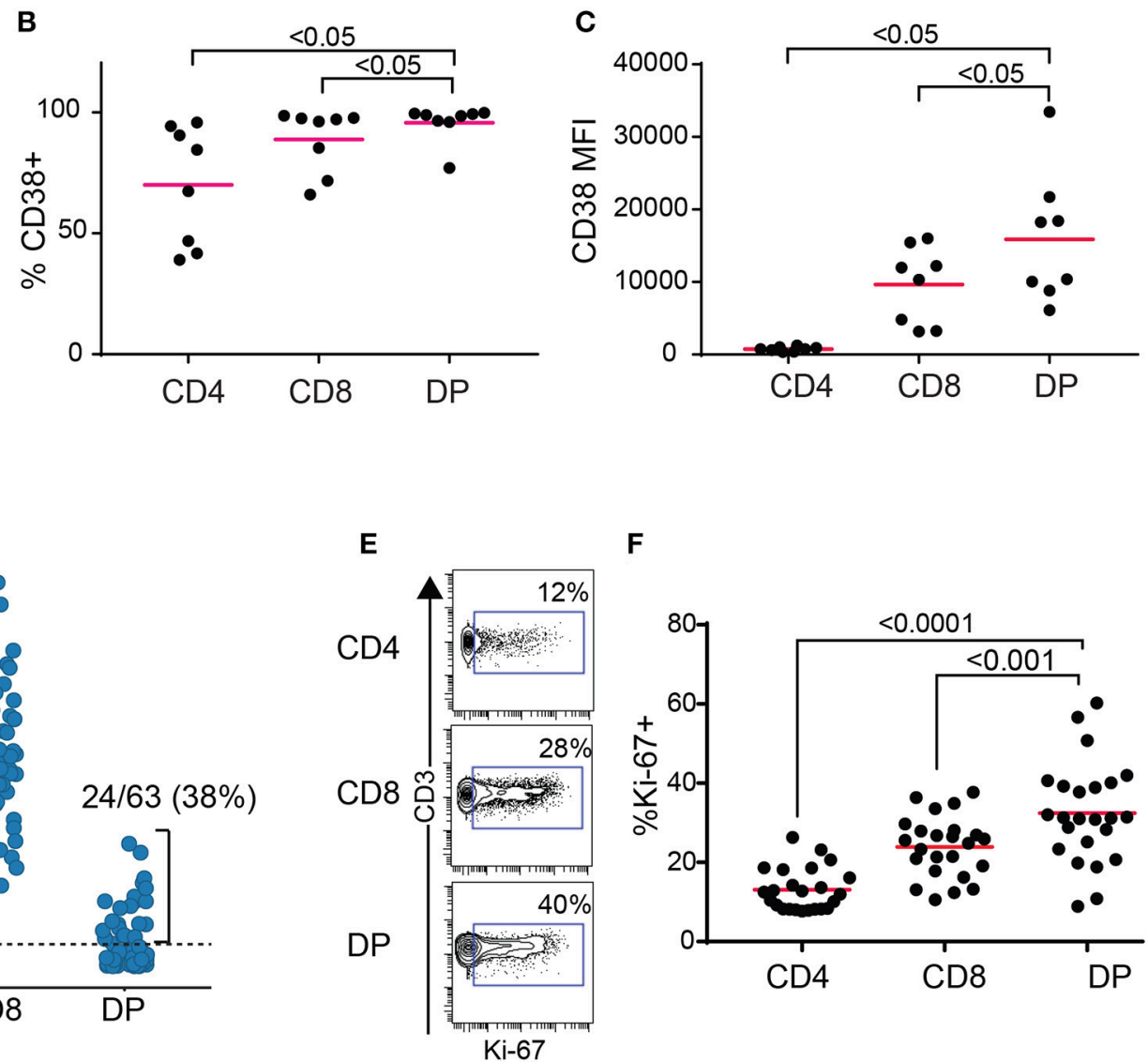

$\mathbf{F}$
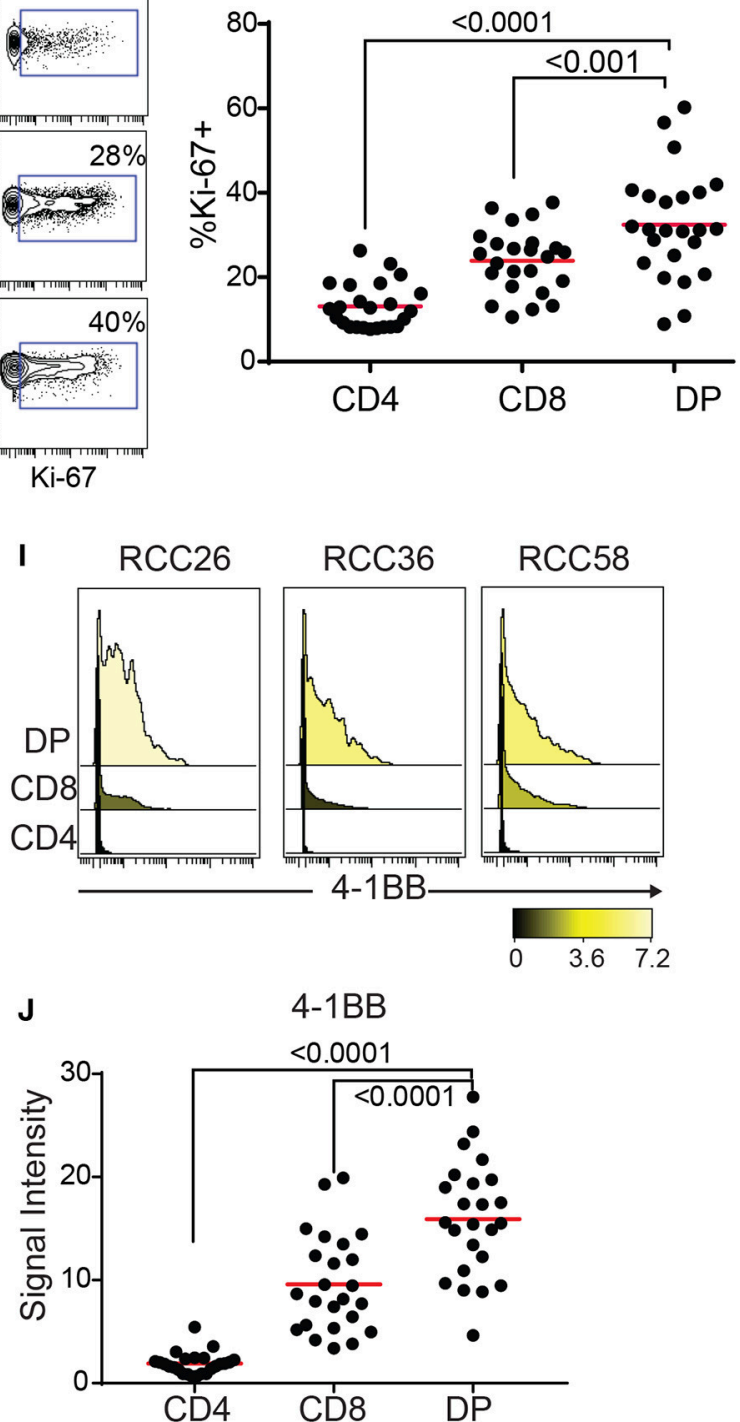

FIGURE 4 | DP T cells show markers of activation. (A-C) CD38 expression by CD4, CD8 and DP T cells in 8/10 samples from replication cohort with > 5\% DP T cells. (A) Representative histogram of CD38 expression in the 3 subsets of T cells. The color bar represents the median fluorescence intensity (MFI). (B) Frequencies of CD38+ and (C) CD38 MFI in CD38+ cells for the 3 subsets for samples with > 5\% DP. (D) Frequencies of CD4+, CD8+, and DP T cells (of TIL CD3+ T cells) in a 
FIGURE 4 | publicly available RCC dataset (20). Only samples with $>1,000 \mathrm{CD} 3+\mathrm{T}$ cells were used $(N=63)$. The dotted line at $5 \%$ is the cutoff used to determine expansion of DP T cells. (E) Representative density plot for Ki-67 for CD4, CD8 and DP T cells. The gate represents the Ki-67+ cells and the number is the frequencies of cells in the Ki-67+ gate. (F) Summary of \%Ki-67+ cells in CD4, CD8 and DP T cells for samples with more than 5\% DP. (G) Representative histogram of HLA-DR expression for CD4, CD8, and DP T cells from 3 samples. The color bar represents the signal intensity. (H) Summary of HLA-DR signal intensity in CD4, CD8 and DP T cells. (I) Representative histogram of 4-1BB expression for CD4, CD8 and DP T cells from 3 samples. The color bar represents the signal intensity. (J) Summary of 4-1BB signal intensity in CD4, CD8, and DP T cells. For F-J, only samples with >5\% DP cells were used. Adjusted p values are indicated on plots (Wilcoxon test).

\section{A}
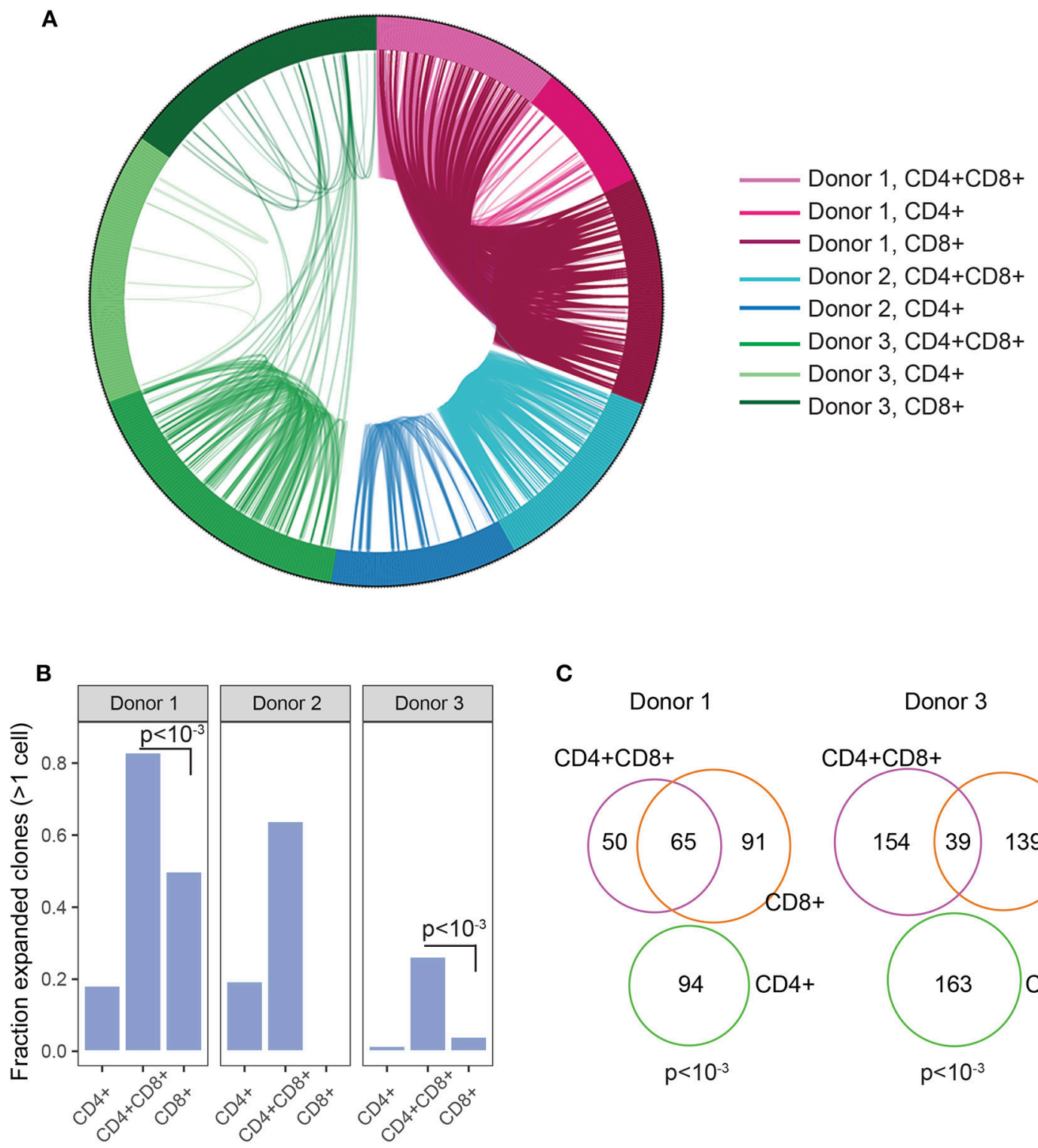

C

Donor 1

Donor 3

CD4+CD8+

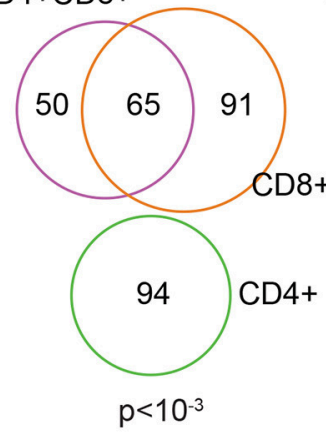

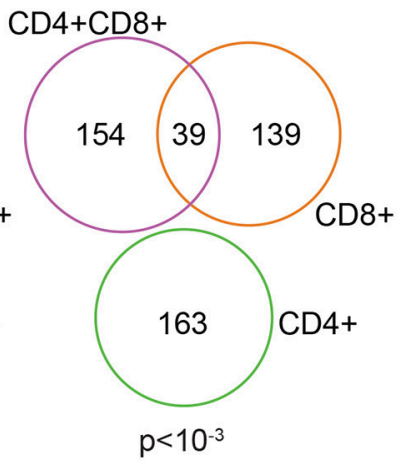

FIGURE 5 | Clonal expansion in DP T cells. (A) Plot showing TCR sharing across CD4, CD8, and DP subsets from 3 donors. Each segment of the circle represents a cell with a rearranged TCR sequence and identical TCR rearrangements are connected with an arc. (B) Fraction of expanded clones across CD4, CD8, and CD4+CD8+ DP T subsets and donors. Clonal expansion was significantly higher in DP than in CD8 T cells in donor1 and donor3 ( $p<10^{-3}$, indicated on plots) (C) Venn diagram representing TCR junction sharing across CD4+ (green circle), CD8+ (orange circle) and CD4+CD8+DP (purple circle) T cell subsets for donor 1 and donor 3. Numbers represent the number of TCR junctions analyzed. Fischer's $p$ values are indicated on plot.

$(43,44)$. PD-1 and TIM-3 were also more highly expressed by conventional CD8 T cells from patients with expanded DP T cells. These markers are upregulated following $\mathrm{T}$ cell activation, which is consistent with the rest of the phenotype of DP T cells. Higher Ki-67 staining in DP T cells suggests recent proliferation as Ki-67 staining will increase after 1 day and stay high for 3-6 days in the 


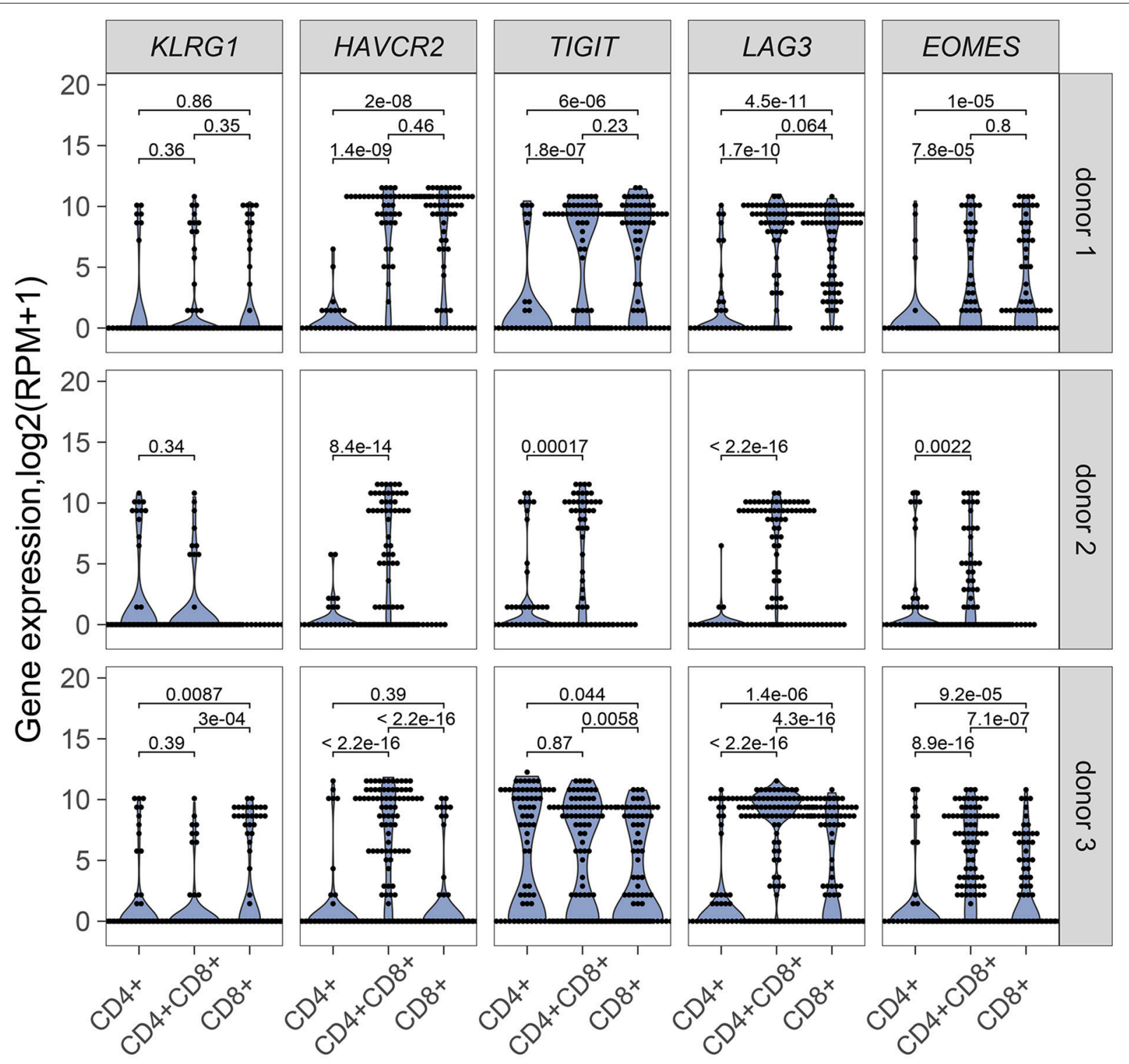

FIGURE 6 | mRNA expression of inhibitory receptor genes KLRG1, HAVRC2, TIGIT, LAG3 and transcription factor gene EOMES in single CD4+, CD8+ and CD4+CD8+ DP T cells from donor 1 and donor 3 and in single CD4+ and CD4+CD8+ DP T cells from donor 2. Unpaired Wilcoxon test was used, p values are indicated on plots.

presence of TCR stimulation $(45,46)$, following similar kinetics of expression as TIM-3 and PD-1. In chronically HIV infected patients, a majority of circulating Ki-67+ CD4 T cells were not actively proliferating but arrested in G1 phase of the cell cycle (47). In addition, Ki-67+ T cells expressing TIM-3 were enriched in HIV-1 infected patients. TIM-3 $+\mathrm{Ki}-67+\mathrm{T}$ cells appeared dysfunctional and did not proliferate or expressed higher IFN $\gamma$ upon in vitro re-stimulation (43). Consistent with these findings, compared to their TIM-3- counterparts, PD-1+TIM-3+ CD8 T cells from RCC tumors were shown to respond poorly to antiCD3 and anti-CD28 stimulation as measured by IFN $\gamma$ secretion. In addition, the presence of this PD-1+TIM-3+ CD8 subset was a marker of worse prognosis in RCC patients (48). Blockade of TIM-3 and PD-1 can reverse T cell dysfunction $(49,50)$ and high expression of PD-1 in TIL predicts response to PD-1 blockade (7). Although this hypothesis needs to be tested with functional assays, according to this published literature, high expression of PD-1 and TIM-3 on DP T cells may inhibit their function, which could be restored by blockade of inhibitory receptors. In Type 1 diabetes patients treated with teplizumab, responders showed a population of CD8 memory $\mathrm{T}$ cells that expressed EOMES and inhibitory receptors and retained some effector function as shown by IFNG and GZB expression, like the DP T cells in this study (51). 
A

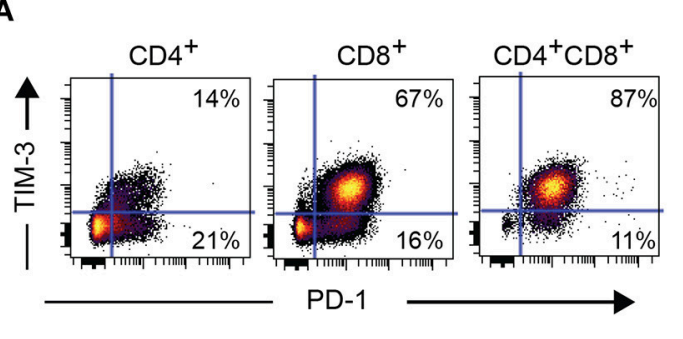

B

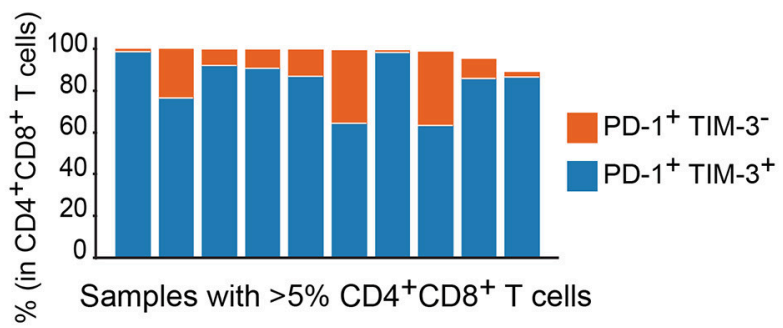

C

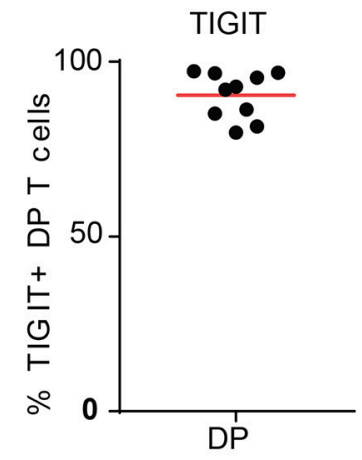

E

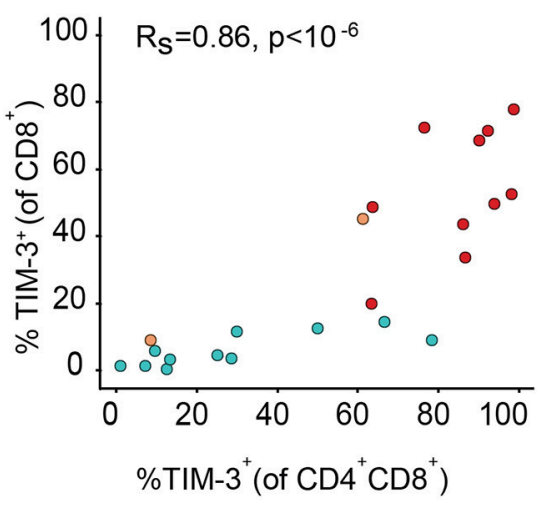

D

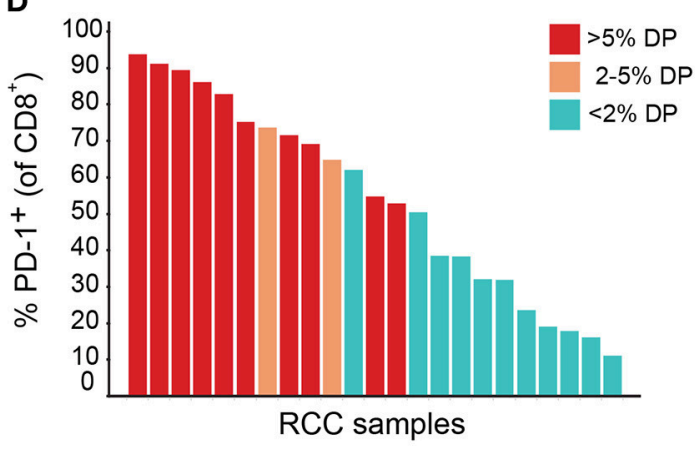

$\mathbf{F}$

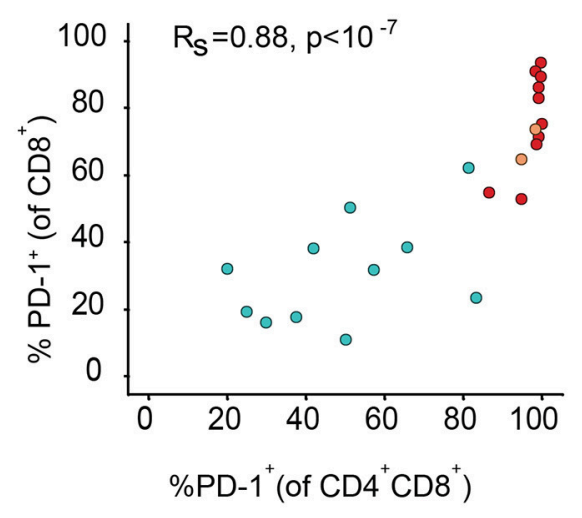

FIGURE 7 | DP T cells co-express inhibitory receptors PD-1 and TIM-3. (A) Representative dot plot of PD-1 (x-axis) and TIM-3 (y-axis) in CD4+, CD8+, and DP T cells. (B) Summary of PD-1+ TIM-3+ and PD-1+ TIM-3- DP T-cell frequencies for RCC samples with >5\% DP cells. (C) Frequencies of TIGIT+ CD4+CD8+ DP T cells. (D) Frequencies of PD-1+ CD8+ T cells in RCC samples with $>5 \%$ DP T cells (red), $2-5 \%$ DP T cells (orange) and $<2 \%$ DP T cells (aqua). (E,F) Correlation of TIM-3 (E) and PD-1 (F) expressions on CD4+CD8+DP and CD8+ T cells. Rs and P-value for Spearman correlations are shown on graphs.

In conclusion, these results suggest that DP $\mathrm{T}$ cells might potentially be a subset of dysfunctional tumor antigen-specific CD8+ $\mathrm{T}$ cells with the potential to be reactivated by treatment with checkpoint inhibitors. A CD4/CD8 duplex immunohistochemistry assay might enable us to predict response to checkpoint inhibitors in RCC in the future.

\section{ETHICS STATEMENT}

This study was carried out in accordance with the recommendations of each provider's Institutional Review Board (IRB) (providers were BRI, Folio-Conversant, MT Group,
CINJ) with written informed consent from all subjects. All subjects gave written informed consent in accordance with the Declaration of Helsinki. The protocol was approved by the IRB.

\section{AUTHOR CONTRIBUTIONS}

LM, PF, PL, EW, BP, NM, and SN planned and designed experiments. PF, BK, EW, ML, BR, and BP performed experiments. LM, PF, BK, PL, EW, BP, and DL analyzed results. LM wrote the manuscript. PL, EW, NM, and SN provided intellectual input and helped preparing the manuscript. 


\section{FUNDING}

This work was funded by Bristol-Myers Squibb.

\section{ACKNOWLEDGMENTS}

We thank patients for donating samples; Dawn Stetsko, Gaurav Singh, Can Jiang, Jonathan Pabalan, Olivia Linton and Cheryl

\section{REFERENCES}

1. Borghaei H, Paz-Ares L, Horn L, Spigel DR, Steins M, Brahmer JR, et al. Nivolumab versus docetaxel in advanced nonsquamous non-small-cell lung cancer. N Engl J Med. (2015) 373:1627-39. doi: 10.1056/NEJMoa1507643

2. Brahmer J, Reckamp KL, Baas P, Crino L, Eberhardt WE, Spigel DR, et al. Nivolumab versus docetaxel in advanced squamous-cell non-small-cell lung cancer. N Engl J Med. (2015) 373:123-35. doi: 10.1056/NEJMoa1504627

3. Hodi FS, Chesney J, Pavlick AC, Robert C, Grossmann KF, McDermott DF, et al. Combined nivolumab and ipilimumab versus ipilimumab alone in patients with advanced melanoma: 2-year overall survival outcomes in a multicentre, randomised, controlled, phase 2 trial. Lancet Oncol. (2016) 17:1558-68. doi: 10.1016/S1470-2045(16)30366-7

4. Hui R, Garon EB, Goldman JW, Leighl NB, Hellmann MD, Patnaik A, et al. Pembrolizumab as first-line therapy for patients with PD-L1-positive advanced non-small cell lung cancer: a phase 1 trial. Ann Oncol. (2017) 28:874-81. doi: 10.1093/annonc/mdx008

5. Yarchoan M, Hopkins A, Jaffee E M. Tumor mutational burden and response rate to PD-1 inhibition. $N$ Engl J Med. (2017) 377:2500-1. doi: 10.1056/NEJMc1713444

6. Snyder A, Makarov V, Merghoub T, Yuan J, Zaretsky JM, Desrichard A, et al. Genetic basis for clinical response to CTLA-4 blockade in melanoma. N Engl J Med. (2014) 371:2189-99. doi: 10.1056/NEJMoa1406498

7. Thommen DS, Koelzer VH, Herzig P, Roller A, Trefny M, Dimeloe S, et al. A transcriptionally and functionally distinct PD-1(+) CD8(+) T cell pool with predictive potential in non-small-cell lung cancer treated with PD-1 blockade. Nat Med. (2018) 24:994-1004. doi: 10.1038/s41591-018-0057-Z

8. Simoni Y, Becht E, Fehlings M, Loh CY, Koo SL, Teng KWW, et al. Bystander CD8(+) T cells are abundant and phenotypically distinct in human tumour infiltrates. Nature (2018) 557:575-9. doi: 10.1038/s41586-018-0130-2

9. Cheroutre H, Husain MM. CD4 CTL: living up to the challenge. Semin Immunol. (2013) 25:273-81. doi: 10.1016/j.smim.2013

10. Overgaard NH, Jung JW, Steptoe RJ, Wells JW. CD4+/CD8+ double-positive T cells: more than just a developmental stage? J Leukoc Biol. (2015) 97:31-8. doi: 10.1189/jlb.1RU0814-382

11. Cervantes-Barragan L, Chai JN, Tianero MD, Di Luccia B, Ahern PP, Colonna, $\mathrm{M}$, et al. Lactobacillus reuteri induces gut intraepithelial CD4(+)CD8alphaalpha(+) $\quad \mathrm{T}$ cells. Science (2017) 357:806-10. doi: $10.1126 /$ science.aah5825

12. Kitchen SG, Jones NR, LaForge S, Whitmire JK, Vu BA, Brooks DG, et al. CD4 on CD8(+) T cells directly enhances effector function and is a target for HIV infection. Proc Natl Acad Sci USA. (2004) 101:8727-32. doi: 10.1073/pnas.0401500101

13. Nascimbeni M, Shin EC, Chiriboga L, Kleiner DE, Rehermann B. Peripheral $\mathrm{CD} 4(+) \mathrm{CD} 8(+) \mathrm{T}$ cells are differentiated effector memory cells with antiviral functions. Blood (2004) 104:478-86. doi: 10.1182/blood-2003-1 2-4395

14. Zloza A, Schenkel JM, Tenorio AR, Martinson JA, Jeziorczak PM, Al-Harthi L. Potent HIV-specific responses are enriched in a unique subset of CD8+ $\mathrm{T}$ cells that coexpresses CD4 on its surface. Blood (2009) 114:3841-53. doi: 10.1182/blood-2009-02-202481

15. Desfrancois J, Derre L, Corvaisier M, Le Mevel B, Catros V, Jotereau F, et al. Increased frequency of nonconventional double positive CD4CD8 alphabeta $\mathrm{T}$ cells in human breast pleural effusions. Int J Cancer (2009) 125:374-80. doi: $10.1002 /$ ijc. 24366
Rizzo for processing tumors for TIL extraction; Yuko Ishii and Megan Wind-Rotolo for critical reading of the manuscript.

\section{SUPPLEMENTARY MATERIAL}

The Supplementary Material for this article can be found online at: https://www.frontiersin.org/articles/10.3389/fimmu. 2018.02728/full\#supplementary-material

16. Desfrancois J, Moreau-Aubry A, Vignard V, Godet Y, Khammari A, Dreno $\mathrm{B}$, et al. Double positive CD4CD8 alphabeta T cells: a new tumorreactive population in human melanomas. PLOS ONE (2010) 5:e8437. doi: 10.1371/journal.pone.0008437

17. Sarrabayrouse G, Corvaisier M, Ouisse LH, Bossard C, Le Mevel B, Potiron L, et al. Tumor-reactive CD4+ CD8alphabeta+ CD103+ alphabetaT cells: a prevalent tumor-reactive T-cell subset in metastatic colorectal cancers. Int J Cancer (2011) 128:2923-32. doi: 10.1002/ijc.25640

18. Parrot T, Oger R, Benlalam HD, Raingeard de la Bletiere, Jouand N, Coutolleau A, et al. (2016). CD40L confers helper functions to human intra-melanoma class-I-restricted CD4(+)CD8(+) double positive T cells. Oncoimmunology 5:e1250991. doi: 10.1080/2162402X.2016.1250991

19. Parrot T, Allard M, Oger R, Benlalam HD, Raingeard de la Bletiere, Coutolleau A, et al. IL-9 promotes the survival and function of human melanomainfiltrating CD4(+) CD8(+) double-positive T cells. Eur J Immunol. (2016) 46:1770-82. doi: 10.1002/eji.201546061

20. Chevrier S, Levine JH, Zanotelli VRT, Silina K, Schulz D, et al. An immune atlas of clear cell renal cell carcinoma. Cell (2017) 169:736-49 e718. doi: 10.1016/j.cell.2017.04.016

21. Qiu P, Simonds EF, Bendall SC, Gibbs KD Jr, Bruggner R, Linderman MD, et al. Extracting a cellular hierarchy from high-dimensional cytometry data with SPADE. Nat Biotechnol. (2011) 29:886-91. doi: 10.1038/nbt.1991

22. Zloza A, Al-Harthi L. Multiple populations of T lymphocytes are distinguished by the level of CD4 and CD8 coexpression and require individual consideration. J Leukoc Biol. (2006) 79:4-6. doi: 10.1189/jlb.0805455

23. Boasso A, Hardy AW, Anderson SA, Dolan MJ, Shearer GM. HIVinduced type I interferon and tryptophan catabolism drive $\mathrm{T}$ cell dysfunction despite phenotypic activation. PLoS ONE (2008) 3:e2961. doi: 10.1371/journal.pone.0002961

24. Han A, Newell EW, Glanville J, Fernandez-Becker N, Khosla C, Chien YH, et al. Dietary gluten triggers concomitant activation of CD4+ and CD8+ alphabeta T cells and gammadelta T cells in celiac disease. Proc Natl Acad Sci USA. (2013) 110:13073-8. doi: 10.1073/pnas.1311861110

25. Yang J, Wen X, Xu H, Torres-Chinn N, Speake C, Greenbaum C, et al. Antigen-Specific $\mathrm{T}$ cell analysis reveals that active immune responses to beta cell antigens are focused on a unique set of epitopes. J Immunol. (2017) 199:91-6. doi: 10.4049/jimmunol.1601570

26. Wieland A, Kamphorst AO, Adsay NV, Masor JJ, Sarmiento J, Nasti TH, et al. $\mathrm{T}$ cell receptor sequencing of activated CD8 $\mathrm{T}$ cells in the blood identifies tumor-infiltrating clones that expand after PD-1 therapy and radiation in a melanoma patient. Cancer Immunol Immunother. (2018) 67:1767-76. doi: 10.1007/s00262-018-2228-7

27. Ye Q, Song DG, Poussin M, Yamamoto T, Best A, Li C, et al. CD137 accurately identifies and enriches for naturally occurring tumor-reactive T cells in tumor. Clin Cancer Res. (2014) 20:44-55. doi: 10.1158/1078-0432.CCR-13-0945

28. Pearce EL, Mullen AC, Martins GA, Krawczyk CM, Hutchins AS, Zediak VP, et al. Control of effector CD8 $+\mathrm{T}$ cell function by the transcription factor eomesodermin. Science (2003) 302:1041-3. doi: 10.1126/science.1090148

29. Duhen T, Duhen R, Montler R, Moses J, Moudgil T, de Miranda $\mathrm{N}$, et al. Co-expression of CD39 and CD103 identifies tumor-reactive CD8 T cells in human solid tumors. Nat Commun. (2018) 9:2724. doi: 10.1038/s41467-018-05072-0

30. Mami-Chouaib F, Blanc C, Corgnac S, Hans S, Malenica I, Granier C, et al. Resident memory $\mathrm{T}$ cells, critical components in tumor immunology. $J$ Immunother Cancer (2018) 6:87. doi: 10.1186/s40425-018-0399-6 
31. Sullivan YB, Landay AL, Zack JA, Kitchen SG, Al-Harthi L. Upregulation of $\mathrm{CD} 4$ on $\mathrm{CD} 8+\mathrm{T}$ cells: CD4dimCD8bright $\mathrm{T}$ cells constitute an activated phenotype of CD8+ T cells. Immunology (2001) 103:270-80. doi: 10.1046/j.1365-2567.2001.01243.x

32. Wherry EJ, Ahmed R. Memory CD8 T-cell differentiation during viral infection. J Virol. (2004) 78:5535-45. doi: 10.1128/JVI.78.11.5535-5545.2004

33. Garrido F, Aptsiauri N, Doorduijn EM, Garcia Lora AM, van Hall T. The urgent need to recover MHC class I in cancers for effective immunotherapy. Curr Opin Immunol. (2016) 39:44-51. doi: 10.1016/j.coi.2015. 12.007

34. Wang QJ, Hanada K, Robbins PF, Li YF, Yang JC. Distinctive features of the differentiated phenotype and infiltration of tumor-reactive lymphocytes in clear cell renal cell carcinoma. Cancer Res. (2012) 72:6119-29. doi: 10.1158/0008-5472.CAN-12-0588

35. Turajlic S, Litchfield $\mathrm{K}, \mathrm{Xu} \mathrm{H}$, Rosenthal R, McGranahan N, Reading $\mathrm{J}$, et al. Insertion-and-deletion-derived tumour-specific neoantigens and the immunogenic phenotype: a pan-cancer analysis. Lancet Oncol. (2017) 18:1009-21. doi: 10.1016/S1470-2045(17)30516-8

36. McDermott DF, Huseni MA, Atkins MB, Motzer RJ, Rini BI, Escudier B, et al. Clinical activity and molecular correlates of response to atezolizumab alone or in combination with bevacizumab versus sunitinib in renal cell carcinoma. Nat Med. (2018) 24:749-57. doi: 10.1038/s41591-018-0053-3

37. Cantalupo PG, Katz JP, Pipas JM. Viral sequences in human cancer. Virology (2018) 513:208-16. doi: 10.1016/j.virol.2017.10.017

38. Alibek K, Karatayeva N, Bekniyazov I. The role of infectious agents in urogenital cancers. Infect Agent Cancer (2012) 7:35. doi: 10.1186/1750-9378-7-35

39. Kassiotis G. Endogenous retroviruses and the development of cancer. $J$ Immunol. (2014) 192:1343-9. doi: 10.4049/jimmunol.1302972

40. Takahashi Y, Harashima N, Kajigaya S, Yokoyama H, Cherkasova E, McCoy J, et al. Regression of human kidney cancer following allogeneic stem cell transplantation is associated with recognition of an HERV-E antigen by $\mathrm{T}$ cells. J Clin Invest. (2008) 118:1099-109. doi: 10.1172/JCI34409

41. Rooney MS, Shukla SA, Wu CJ, Getz G, Hacohen N. Molecular and genetic properties of tumors associated with local immune cytolytic activity. Cell (2015) 160:48-61. doi: 10.1016/j.cell.2014.12.033

42. Cherkasova E, Scrivani C, Doh S, Weisman Q, Takahashi Y, Harashima N, Childs R, W. et al. Detection of an Immunogenic HERV-E envelope with selective expression in clear cell kidney cancer. Cancer Res. (2016) 76:2177-85. doi: 10.1158/0008-5472.CAN-15-3139

43. Jones RB, Ndhlovu LC, Barbour JD, Sheth PM, Jha AR, Long BR, et al. Tim-3 expression defines a novel population of dysfunctional $\mathrm{T}$ cells with highly elevated frequencies in progressive HIV-1 infection. J Exp Med. (2008) 205:2763-79. doi: 10.1084/jem.20081398

44. Ahmadzadeh M, Johnson LA, Heemskerk B, Wunderlich JR, Dudley ME, White DE, et al. Tumor antigen-specific CD8 T cells infiltrating the tumor express high levels of PD-1 and are functionally impaired. Blood (2009) 114:1537-44. doi: 10.1182/blood-2008-12-195792

45. Soares A, Govender L, Hughes J, Mavakla W, de Kock M, Barnard C, Pienaar B, et al. Novel application of Ki67 to quantify antigenspecific in vitro lymphoproliferation. J Immunol Methods (2010) 362:43-50. doi: $10.1016 /$ j.jim.2010.08.007

46. Lastovicka J, Rataj M, Bartunkova J. Assessment of lymphocyte proliferation for diagnostic purpose: Comparison of CFSE staining, Ki-67 expression and (3)H-thymidine incorporation. Hum Immunol. (2016) 77:1215-22. doi: 10.1016/j.humimm.2016.08.012

47. Combadere B, Blanc C, Li T, Carcelain G, Delaugerre C, Calvez $\mathrm{V}$, et al. CD4+Ki67+ lymphocytes in HIV-infected patients are effector $\mathrm{T}$ cells accumulated in the $\mathrm{G} 1$ phase of the cell cycle. Eur J Immunol. (2000) 30:3598-603. doi: 10.1002/1521 -4141(200012)30:12<3598::AID-IMMU3598>3.0.CO;2-E

48. Granier C, Dariane C, Combe P, Verkarre V, Urien S, Badoual C, et al. Tim3 expression on tumor-infiltrating $\mathrm{PD}-1(+) \mathrm{CD} 8(+) \mathrm{t}$ cells correlates with poor clinical outcome in renal cell carcinoma. Cancer Res. (2017) 77:1075-82. doi: 10.1158/0008-5472.CAN-16-0274

49. Fourcade J, Sun Z, Benallaoua M, Guillaume P, Luescher IF, Sander C, et al. Upregulation of Tim-3 and PD-1 expression is associated with tumor antigenspecific CD8+ T cell dysfunction in melanoma patients. J Exp Med. (2010) 207:2175-86. doi: 10.1084/jem.20100637

50. Sakuishi K, Apetoh L, Sullivan JM, Blazar BR, Kuchroo VK, Anderson AC. Targeting Tim-3 and PD-1 pathways to reverse $\mathrm{T}$ cell exhaustion and restore anti-tumor immunity. J Exp Med. (2010) 207:2187-94. doi: 10.1084 /jem. 20100643

51. Long SA, Thorpe J, DeBerg HA, Gersuk V, Eddy J, Harris KM, et al. Partial exhaustion of CD8 T cells and clinical response to teplizumab in new-onset type 1 diabetes. Sci Immunol. (2016) 1:eaai7793. doi: 10.1126/sciimmunol.aai7793

Conflict of Interest Statement: LM, PF, BK, DL, BP, NM, SN are BMS employees. $\mathrm{PL}$ and EW received funding from BMS.

The remaining authors declare that the research was conducted in the absence of any commercial or financial relationships that could be construed as a potential conflict of interest.

Copyright (c) 2018 Menard, Fischer, Kakrecha, Linsley, Wambre, Liu, Rust, Lee, Penhallow, Manjarrez Orduno and Nadler. This is an open-access article distributed under the terms of the Creative Commons Attribution License (CC BY). The use, distribution or reproduction in other forums is permitted, provided the original author(s) and the copyright owner(s) are credited and that the original publication in this journal is cited, in accordance with accepted academic practice. No use, distribution or reproduction is permitted which does not comply with these terms. 